THE WILDERNESS INSTRUCTOR

\title{
Climbing the Education Mountain: Designing the New Diploma in Mountain Medicine for the United Kingdom
}

\author{
Kyle Pattinson, BM, FRCA; Sarah Matthews, BSc, MBBS, MRCGP \\ From the University Hospitals, Coventry and Warwickshire NHS Trust, Department of Anesthesia, Coventry, United Kingdom (Dr Pattinson); \\ and the Centre for Primary Health Care Studies, The Medical School, The University of Warwick, Acting Senior Lecturer, Coventry, United \\ Kingdom (Dr Matthews).
}

\begin{abstract}
This article aims to use educational theory to help plan the course for the new Diploma in Mountain Medicine in the United Kingdom. The course is administered by Medical Expeditions, a charity devoted to mountain medicine education and research. One of the authors (K.P.) is a member of the faculty for the Diploma in Mountain Medicine.
\end{abstract}

Key words: mountain medicine education, United Kingdom

\section{Introduction}

The aim of the Diploma in Mountain Medicine (DMM) course is "to give registered medical practitioners the theoretical and practical knowledge to manage the specific illnesses and diseases that may occur in the mountain environment." It was felt that a formal qualification in mountain medicine was necessary owing to the increasing numbers of people visiting mountainous areas, often on commercial expeditions. In addition, an increased awareness in clinical governance has highlighted the importance of doctors having the appropriate training for the work that they perform. It is intended that a national register of diploma holders be set up as a source of advice to patients and other doctors.

Practical mountain medicine in the United Kingdom (UK) is different from that in the European Alps and North America, because mountain rescue teams in the UK are volunteer based (unlike the professional teams that operate in the European Alps), and the weather conditions during the Scottish winter are wet as well as cold.

During 1997, the Union Internationale des Associations Alpinistes (UIAA), Internationale Kommission fur Alipines Rettungswesen (IKAR [International Organisation for Mountain Rescue]), and the International Society for Mountain Medicine (ISMM) formulated a syl-

Corresponding author: Kyle Pattinson, BM, FRCA, University Hospitals, Coventry and Warwickshire NHS Trust, Clifford Bridge Road, CV2 2DX, Coventry, United Kingdom (e-mail: kyletsp@postmaster. co.uk). labus for an international DMM. This document laid down minimum requirements for a course in mountain medicine to achieve approval for award of the UIAAIKAR-ISMM DMM. Approved courses have been set up throughout Europe, and although they all fulfill the minimum requirements, there is great variation in terms of the length of the course and assessment. Some of these courses confer university academic qualification in addition to the UIAA-IKAR-ISMM accreditation. ${ }^{1,2}$ To date, there have been no accredited mountain medicine courses in the UK. A 3-day theoretical course has run at the Plas Y Brenin National Mountain Centre (PYB) since 1993, and a 4-day practical course has run in Scotland since 1997.

The course for the new UK DMM has been approved for UIAA-IKAR-ISMM accreditation. It has also been approved as a postgraduate certificate by the University of Leicester. The first formal course will commence in November 2003, and this article builds on experiences gained during the trial run of the course.

The course has been designed to take place in 4 separate modules of formal student contact, each lasting approximately 1 week. Two weeks are devoted to the medical aspects of the course, to be held at the PYB, and the other 2 weeks are mainly devoted to assessment of personal mountaineering skills by mountain guides in the Alps and in Scotland. Mountaineering skills are an important aspect of the course, because "in order to take care of other people in the mountains, you must be able to take care of yourself." 3 


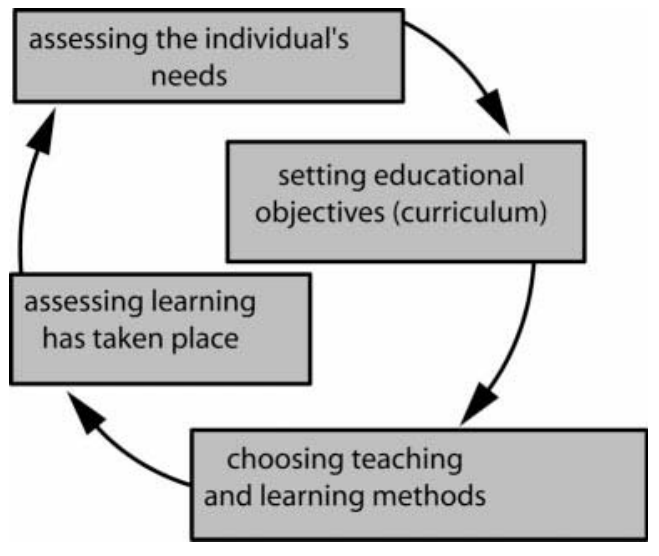

Figure 1. The educational cycle.

\section{The educational cycle}

The term educational cycle describes the process of setting educational objectives, choosing the methods to achieve these objectives (teaching and learning), and checking that these objectives have been fulfilled (assessment). This process is shown in Figure 1. For educational activity to be effective, these components of the educational cycle need to be considered when planning a course.

This article concentrates on choosing teaching and learning methods and assessing that learning has taken place for the medical aspects of the course. The educational needs and objectives have largely been defined by the UIAA-IKAR-ISMM committee, with material added to make the course relevant to the areas in which British mountain doctors are likely to practice.

\section{Choosing teaching and learning methods}

$\mathrm{Kolb}^{4}$ described the adult learning process as cyclical. "Concrete experience" is followed by "reflective observation," "abstract conceptualization," and finally "active experimentation," at which point the learning cycle starts again (Figure 2).

Different individuals learn in different ways. This concept has been described by various authors, notably Honey and Mumford, ${ }^{5}$ who ascribed different learners preferences for different stages of the cycle. Effective adult learning requires traveling around this learning cycle. Varying the teaching and learning methods of a course will help compensate for differences in learning styles and encourage learning at different stages of the cycle.

It is also important to consider adult learning theories (eg, Knowles $\left.{ }^{6}\right)$. Kaufman ${ }^{7}$ used these theories to de-

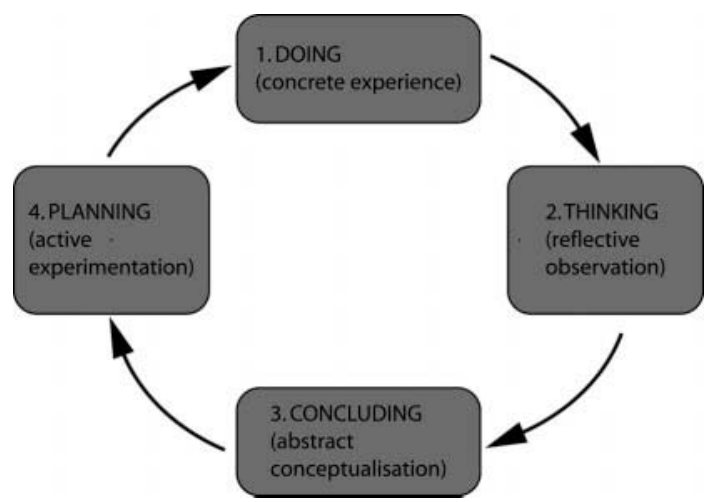

Figure 2. Kolb's learning cycle.

scribe "seven principles to guide teaching practice." These principles are as follows:

- the learner should be an active contributor to the educational process;

- learning should closely relate to understanding and solving real-life problems;

- learners' knowledge and experience are critical in new learning situations;

- self-direction is important;

- practice, self-assessment, and feedback are important;

- learners should be given an opportunity for reflection; and

- role models are important.

The new course for the DMM is ideally suited to fulfill these goals. The curriculum covers a range of topics, from theoretical to practical, so that different learning styles can easily be accommodated. Ample opportunity is also available to take teaching beyond the boundaries of the classroom and into the mountains.

Since 1993, and most years thereafter, a 3-day course, entitled "Mountain and High Altitude Medicine and Physiology," has been held at the PYB. This lecturebased course is attended by approximately 120 delegates and is administered by Medical Expeditions; sessions are taught by expert speakers from around the world. From an educational point of view, lectures are an excellent way of delivering information efficiently. Many of the core subjects for the diploma are dealt with during these 3 days. However, the 3-day course was not designed with the diploma in mind, despite much relevant content. It is intended, however, that this course form the first part of a module for the diploma course. Adults learn best when they are "an active contributor to the educational process," and this is difficult to achieve during a didactic lecture. A problem-based approach is usually more successful than a subject-based approach. Lectures usually lend themselves to this subject-based approach, 
while small group work is ideally suited to problembased learning.

One way to improve the learning experience might be for diploma students to have a sufficient knowledge base prior to attending the course. This can be achieved by self-directed learning prior to the course. The beauty of this method is that it will have no impact on the structure of the 3-day course. Following the 3-day course, the diploma students continue the module for 4 days. Before that, time could be allotted for students to reflect on the previous 3 days. In this way, learners would have traveled around Kolb's learning cycle twice. Another improvement could be to substitute small group sessions for some of the lectures. This inevitably would have cost implications, as more physical space and more teachers or facilitators would be required. With this format, formal lectures could be reserved for keynote speakers, and separate workshops dedicated to the diploma candidates could run without interrupting the flow of the 3-day meeting. In these ways, the educational objectives of the diploma course could be achieved in parallel with those of an improved 3-day course.

Following the 3-day "Mountain and High Altitude Medicine and Physiology" course, the rest of the medical theory teaching is planned to be programmed into the 4 days following that course and into a separate 5day theory module held at a separate time (known as the "Spring Theory Course"). The number of candidates will be between 10 and 20 (as opposed to 120), which will make it more practical to use a variety of teaching methods.

Small group discussion is considered to be a valuable educational tool. Discussion promotes educational autonomy and helps with reflection and idea formation. Working through tasks with other group members encourages teamwork. Discussion also gives learners valuable feedback and is a useful tool to ensure that learning is taking place. ${ }^{8}$ The varied nature of the syllabus will assist with different approaches to group work, which will help accommodate various learning styles. For example, a tutorial on stress management during expeditions could divide the group into smaller groups of 4 or 5 participants who discuss various strategies and then present them back to the main group. A topic such as altitude sickness could be presented as a short lecture highlighting key points, followed by clinical scenarios in which groups discuss management options. Another technique is the "group round," in which each member in turn has a brief time to say something to the group. This technique could be useful as an introduction to a discussion on first-aid kits, in which each member describes and justifies an item in their kit.

Currently, no formal medical theory is programmed

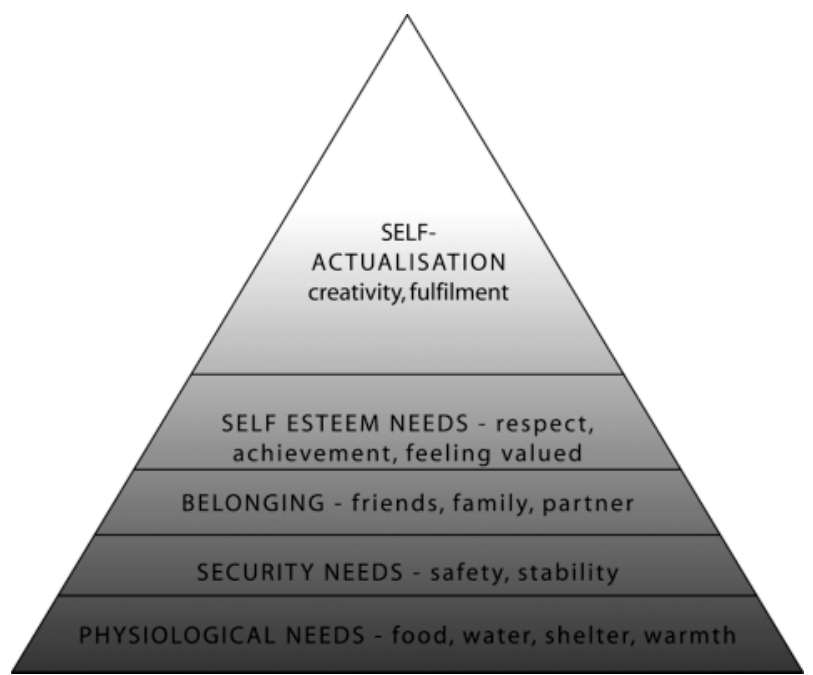

Figure 3. Maslow's hierarchy of human needs.

into the Scottish winter skills module or the Alpine skills module, because it is thought that students will be too tired at the end of a day in the mountains to be able to benefit from further study. However, during the trial run of the Scottish winter skills course, 2 impromptu group sessions have shown that learners will benefit enormously from this extra input.

A practical exercise involved a simulated search-andrescue mission. On a misty Scottish hillside, we were given map references to locate an injured climber. Having located the climber, we were given the task of creating an improvised splint for his fractured femur. On our return to our accommodation that evening, we repeated the procedures for improvised splinting of fractures and discussed and practiced various methods. On another evening, an informal discussion, involving each group member showing the contents of their personal first aid kit, was followed by lively debate.

These 2 examples illustrate the importance of the learning environment to education. Maslow ${ }^{9}$ described a hierarchy of needs for motivating learning (Figure 3). First, a learner's physiological needs must be satisfied (ie, a comfortable environment). In this case, learning on the hillside (uncomfortable, cold, wet) facilitated the learning but was reinforced by the group work the same evening. The other levels of Maslow's hierarchy are safety (an environment in which a student feels safe to speak out), belonging (being part of a group), self-esteem (feeling as a valued member of the group), and self-actualization (for which the other factors combine to provide the ideal learning environment).

The experience from these informal sessions has shown that unstructured small group sessions can provide an excellent learning experience and will be useful 
for many aspects of the diploma course. Sessions following days in the mountains were successful and should be programmed into the course.

Practical skills training is extremely important for a mountain medicine practitioner. Emergencies often take place at night in a remote situation and in poor weather. Rescuers may be tired and cold, and may be suffering the effects of high altitude, and the patient may be suffering a time-critical injury. Medical treatment, including practical procedures, must be fluent, rapid, and automatic, and must be provided with a full understanding of the relevant background theory. One way of achieving these aims is the 5 -step method described by George, ${ }^{10}$ which is used with success in resuscitation courses around the world. This method of teaching will be used in the diploma course for sessions such as splinting of fractures (described above), trauma management, the use of radios, and construction of improvised stretchers. The plan is to incorporate an adapted 1-day "Rescue and Emergency Care" (REC) course during the first theory module. The REC course is an established training course for mountain first aid, and with some adaptation it will be an excellent basis for practical skills training. However, it will be beneficial to extend practical training beyond this planned REC day. One benefit of having the important practical skills taught during the first module is that the skills can then be practiced, reinforced, and applied to varying situations throughout the following 3 modules.

As stated, using varied teaching styles and learning methods is an excellent way to enhance education. Practical sessions can also be adapted to teach topics that usually are taught by a lecture. For example, a session about altitude sickness could be used for construction of an improvised stretcher to carry a casualty off a mountainside, with training in the use of the portable hyperbaric chamber and oxygen delivery apparatus. More imagination may be required for physiology teaching, but many physiological monitoring devices (eg, pulse oximeters) are lightweight, robust, and can easily be carried in a rucksack to demonstrate the altered physiology of altitude.

Self-directed learning is an important aspect of adult education because the learner remains autonomous, is an active contributor to the learning process, and is able to reflect on the work done. With regard to the course, the aim of self-directed learning is to help build on what has been learned in each module and to prepare for the next module. It is also a useful tool for assessing that learning is taking place. More formal course work may be needed for subjects that are difficult to understand, such as physiology. The work could take the form of written assign- ments or, alternatively, a pre-prepared short talk as part of a small group discussion session.

It is intended that all candidates studying for the diploma keep a logbook of all related activity. This logbook is designed to contain information about mountaineering activity and related medical activity, in a similar format to the logbooks required for formal UK mountaineering qualifications. The intention is that this logbook be kept up-to-date following the diploma, which will encourage life-long learning and provide a useful tool for assessment and appraisal.

In summary, the teaching and learning methods that we consider beneficial for the DMM are as follows:

- to include self-directed learning prior to the 3-day PYB course;

- to have more small group sessions during the 3-day course;

- to continue group discussion sessions on the Scottish and Alpine courses as a formal part of the curriculum design; and

- to continue practical skills training throughout each module.

\section{Assessing that learning has taken place}

Assessment is the final step in the educational cycle. Its aim is to verify that learning has taken place. Assessment is also a useful opportunity for reflection on the learning that has taken place and is thus an important developmental activity in its own right. ${ }^{11}$ Following assessment, the educational cycle can continue and learning can proceed effectively.

The UIAA-IKAR-ISMM syllabus for the DMM includes no mention of assessment; however, it is important for the reasons cited that it be an integral part of the course. The aim of assessment is to assess the knowledge, skills, and attitudes that are deemed necessary for the award of the DMM. This assessment may be either formative assessment or summative assessment. Formative assessment can take place at an early or intermediate stage in the course. It is used to assess needs and knowledge base, and to provide feedback to assist with further learning. Summative assessment is regulatory in nature and leads to the award of the DMM. Formative assessment at the beginning of each module will be a useful way to build on the self-directed course work and highlight the important aspects of the module. The methods used can be similar to those used for summative assessment described below. However, cost and time implications may make simpler assessment tools more practical. During the trial run of the Scottish winter skills course, a session was devoted to a written test on snow 
safety and map reading, followed by an immediate discussion of the answers. This approach was successful because students were given the opportunity to learn from the assessment, and it encouraged further self-directed study.

Summative assessment is planned to be integral to the diploma course, with a final test at the end of each module. Assessment must be valid, reliable, and consistent. It must accommodate differences in students, in a similar way to the importance of varying teaching and learning methods. The best way of achieving this goal is to use a variety of formats for assessment. In addition, different assessment formats are suited to testing different areas of the curriculum. Assessment must be an integral part of course design and not something only considered once the course design has been established. It is important that the purpose and methods of assessment be clearly explained beforehand. Surprises are not welcomed by students and do not contribute to the learning process.

Written assessment is one popular format for assessing medical knowledge. The main advantages of this form of assessment are that the whole faculty can contribute to a question bank, ensuring a variety of question styles. Written questions are cheap to produce, although a certain amount of skill and practice is required to formulate valid and reliable questions. Most physicians are familiar with this assessment method.

Although the content of a question is more important than the format, ${ }^{12}$ certain formats are better at examining different areas of knowledge. Multiple-choice questions are popular because they can cover a wide area of the syllabus in a relatively short period of time. However, they are limited in that they can be difficult to construct and validate. There are various different types of multiple-choice questions, which have been shown to have similar levels of reliability. Initially multiple-choice questions can be used as a formative assessment tool, with the aim of directing learning and promoting discussion. Once the multiple-choice questions have been scored, it will be possible to evaluate which questions are the most valid and reliable, such that a useful summative examination can be created in the future. ${ }^{13,14}$ Specific areas of the syllabus that can be useful for this kind of examination are those in which certain facts can be tested (eg, physiology, snow safety, and infectious diseases) or understanding of important facts (eg, "The first thing you would do with a person suffering shortness of breath at Everest base camp is ...,", followed by 5 statements, only 1 being correct).

Short answer questions are another popular format for medical examinations. In contrast to multiple-choice questions, they can be open-ended and can test deeper understanding of a subject. Short answer questions are more time-consuming to answer and to score, and a marking schedule is required to ensure fairness. A marking schedule is a way of scoring written questions in a standardized fashion. Usually, the schedule consists of a sheet detailing the key points of an answer and assigning scores for each point answered correctly. This approach helps ensure that each answer is scored by the same criteria, thus improving the validity of the test.

During the trial run of the Scottish winter skills course, a very simple short answer question format was successfully used. Questions included problem-solving exercises (eg, Which way would you descend the mountain in order to minimize avalanche risk with these weather conditions?), testing people's awareness of the mountain environment (eg, What has the wind direction been over the past week?), and factually based questions (eg, What is the temperature change with altitude?). In future courses, short answer questions will be used in both this format and as longer structured answers with a clear marking schedule to ensure validity and reliability. A sample question could be "Describe and explain the advice you would give to a client suffering angina who says they would like to go on a high-altitude holiday."

Essays are an excellent way to assess a student's understanding of a specific topic and can be used to formulate discussion. Essays are time-consuming and are even more difficult to validate than multiple-choice questions and short answer questions. The most appropriate time to use essays in the DMM is between modules, in order to guide self-directed learning. A marking schedule helps validate the scoring.

Much of the syllabus is practically based and thus lends itself to practical assessment. The closer an assessment is to a real-life situation, the more valid it is considered to be. ${ }^{15}$ It is intended that practical testing be conducted outdoors, making it realistic to the mountain situation. The adapted REC course tests practical skills; however, other areas of the syllabus can also be assessed in this manner. For example, the immediate care of a trauma victim can be examined in this way. The main problem with practical assessment is expense-faculty members, equipment, and simulated patients are required, although space limitations are less of a concern, as we intend to use the mountainside as the examination area. Scoring relies on checklists, which again makes assessment less similar to real life, and the checklists need to be validated so that they are reliable and discriminatory.

The final method of assessment proposed for the DMM is a logbook (or portfolio)-based assessment. The aim of this logbook is to encourage life-long learning 
relevant to mountain medicine and to document the mountaineering and medical experience of the student. It can be used for both formative and summative assessment. As in marking written questions, the criteria must be clearly stated, and the purpose of the logbook must be understood by both student and examiner. Marking schedules are again necessary to ensure validity, reliability, and fairness when used for the diploma award.

In summary, our plans for assessment methods for the DMM are as follows: written assessment in the form of essays between modules as a guide to self-directed learning, a formative written preassessment in the format of multiple-choice questions and short answer questions, written short answer question tests and practical testing as an end-of-module summative assessment, and examination of the logbook in order for the DMM to be awarded.

\section{Conclusions}

This essay has used educational theory to help improve the plans for the new course for the UK UIAA-ISMMIKAR DMM. The ideas presented here will be discussed at the next meeting of the faculty, and we hope will be used to create an exciting and useful course.

\section{Acknowledgments}

The authors thank William Carey for the artwork and David Hillebrandt for support and encouragement.

\section{References}

1. Peters P. Practical aspects in mountain medicine education. Wilderness Environ Med. 2000;11:262-268.

2. Peters P, Plotz W. Mountain medicine in Europe. Wilderness Environ Med. 1998;9:19-27.

3. Donelan S. Rehearsing for mountain rescue: an introduction. Wilderness Environ Med. 2002;13:58.

4. Kolb DA. Experiential Learning: Experience as the Source of Learning and Development. Old Tappan, NJ: Prentice Hall Inc; 1984.

5. Honey P, Mumford A. The Manual of Learning Styles. Berkshire, UK: Peter Honey; 1982.

6. Knowles MS. Andragogy in Action: Applying Modern Principles of Adult Learning. San Francisco, CA: JosseyBass; 1984.

7. Kaufman D. Applying educational theory in practice. BMJ. 2003;326:213-216.

8. Jaques D. Teaching small groups. BMJ. 2003;326:492494.

9. Maslow, AH. Motivation and Personality. New York, NY: Harper \& Row; 1954.

10. George JH. A simple five-step method for teaching clinical skills. Family Med. 2001;33:577-578.

11. Brown S, Race P, Smith B. 500 Tips on Assessment. London, UK: Kogan Page; 1996.

12. Schuwirth L. Written assessment. BMJ. 2003;326:643645.

13. Haladyna TM. Developing and Validating Multiple Choice Questions. Mahwah, NJ: Lawrence Erlbaum Associates; 1999.

14. Fowell SL, Southgate LJ, Bligh JG. Evaluating assessment: the missing link? Med Educ. 1999;33:276-281.

15. Smee S. Skill based assessment. BMJ. 2003;326:703-706. 